\title{
To Evaluate Serum Uric Acid as a Risk Factor For Micro- Vascular Complications of Diabetes Mellitus
}

\author{
Nagendra Singh Chauhan ${ }^{1}$ \\ ${ }^{1}$ Associate Professor, Department of Medicine, FH Medical College, Tundla.
}

\section{Abstract}

Background: Diabetes Mellitus (DM) as a metabolic disorder of multiple etiology, characterized by chronic hyperglycaemia with disturbances of carbohydrate, protein and fat metabolism. The present study was conducted to evaluate serum uric acid as a risk factor for micro- vascular complications of diabetes mellitus. Subjects and Methods: The present study was conducted on 84 patients with type II diabetes mellitus of both genders. $10 \mathrm{ml}$ of blood was obtained for assessment of blood glucose and uric acid level. Results: Age group 40-60 years had 46, 60-80 years had 25 and $>80$ years had 13 patients. Hyperuricemia was positive in 56 and negative in 28. The difference was significant ( $\mathrm{P}<0.05$ ). Out of 56 patients with hypertension, 42 had high and 14 had low serum uric acid level. Out of 28 patients who had not hypertension, 18 had high serum uric acid and 10 had low. The difference was significant $(\mathrm{P}<0.05)$. Among 48 patients who had stroke, 28 had high serum uric acid and 20 had low uric acid. The difference was significant $(\mathrm{P}<0.05)$. Conclusion: Elevated serum uric acid levels in type 2 diabetes mellitus cause more micro vascular and macro vascular complications.

Keywords: Diabetes Mellitus, Uric Acid, Vascular Complications.

Corresponding Author: Dr. Nagendra Singh Chauhan, Associate Professor, Department of Medicine, FH Medical College, Tundla.

Received: May 2019

Accepted: June 2019

\section{Introduction}

World Health Organization (WHO) defines the term Diabetes Mellitus (DM) as a metabolic disorder of multiple etiology, characterized by chronic hyperglycaemia with disturbances of carbohydrate, protein and fat metabolism, resulting from defects in insulin secretion or insulin action or both. ${ }^{[1]}$ Diabetes mellitus is a leading public health problem with increasing incidence and long-term complications such as diabetic nephropathy, diabetic neuropathy, diabetic retinopathy etc. These complications are mainly a consequence of macro vascular and micro vascular damages of the target organs. ${ }^{[2]}$

Recent studies have demonstrated that serum uric acid levels are higher in subjects with prediabetes and early type 2 diabetes than in healthy controls. Hyperuricemia has been also added to the set of metabolic abnormalities associated with insulin resistance or hyperinsulinemia in metabolic syndrome. This study was carried out to evaluate the level of serum uric acid in type 2 Diabetes mellitus patients and to correlate the parameters of diabetic nephropathy like microalbuminuria and serum creatinine levels with uric acid in type 2 Diabetes mellitus subjects. ${ }^{[3]}$

The physiopathology of chronic microvascular complications of T1D is complex, involving the interaction between genetic susceptibility, metabolic, and environmental factors. Many risk factors have already been associated with the development and progression of diabetic nephropathy, such as elevated $\mathrm{HbA} 1 \mathrm{c}$, duration of diabetes, presence of concomitant microvascular complications and elevated albumin excretion rate. ${ }^{[4]}$ The present study was conducted to evaluate serum uric acid as a risk factor for micro- vascular complications of diabetes mellitus.

\section{Subjects and Methods}

The present study was conducted in the department of General Medicine. It comprised of 84 patients with type II diabetes mellitus of both genders. The study was approved from institutional ethical committee. All participants were informed regarding the study and written consent was obtained.

Data such as name, age, gender etc. was recorded. $10 \mathrm{ml}$ of blood was obtained for assessment of blood glucose and uric acid level. Results thus obtained were subjected to statistical analysis. $\mathrm{P}$ value less than 0.05 was considered significant.

\section{Results}

Table 1:Age wise distribution of patients

\begin{tabular}{|l|l|l|}
\hline Age group (Years) & Number & P value \\
\hline $40-60$ & 46 & \multirow{2}{*}{0.01} \\
\hline $60-80$ & 25 & \\
\hline$>80$ & 13 & \\
\hline
\end{tabular}

[Table 1, Figure 1] shows that age group 40-60 years had 46, 
60-80 years had 25 and >80 years had 13 patients. The difference was significant $(\mathrm{P}<0.05)$.

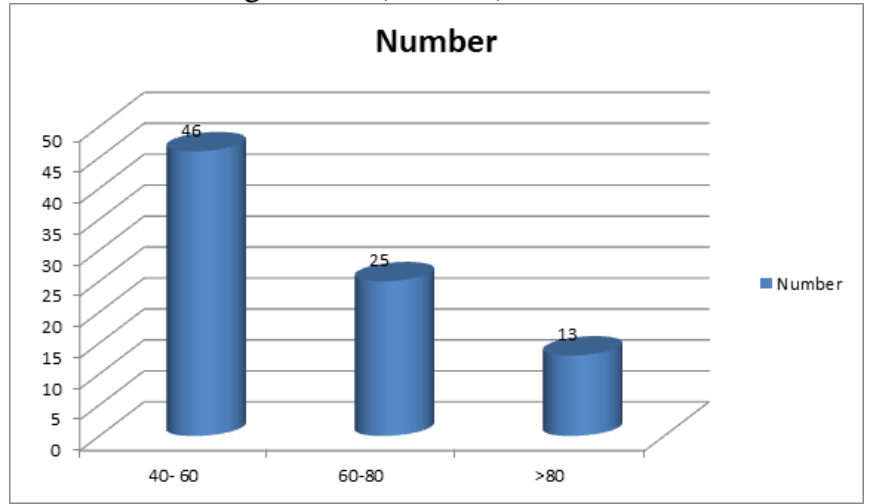

Figure 1: Age wise distribution of patients

Table 2:Association between Hyperuricemia and Diabetes

Mellitus

\begin{tabular}{|l|l|l|}
\hline Hyperuricemia & Number & P value \\
\cline { 1 - 2 } Positive & 56 & 0.01 \\
\hline Negative & 28 & \\
\hline
\end{tabular}

[Table 2, Figure2] shows that hyperuricemia was positive in 56 and negative in 28. The difference was significant $(\mathrm{P}<$ $0.05)$.

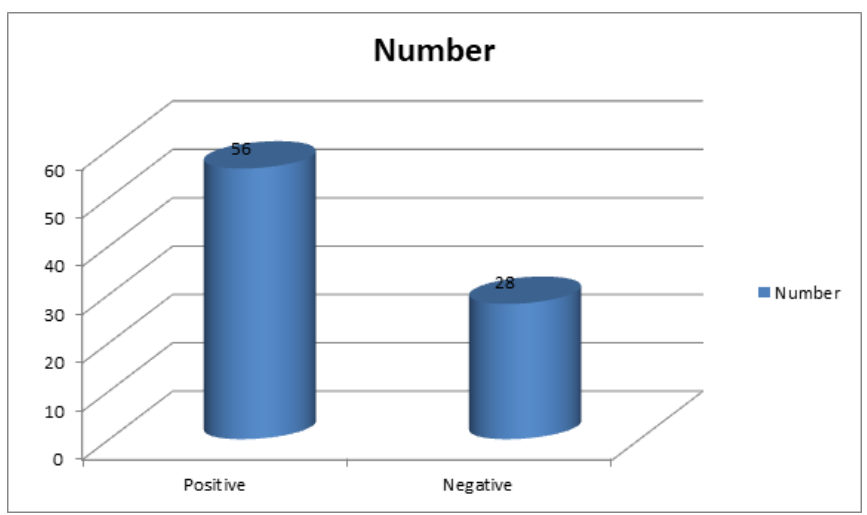

Figure 2:Association between Hyperuricemia and Diabetes Mellitus

Table 3:Association between Hypertension and Serum Uric Acid Levels

\begin{tabular}{|l|l|l|l|}
\hline \multirow{2}{*}{ Hypertension } & \multicolumn{2}{|l|}{ Serum uric acid } & \multirow{2}{*}{ P value } \\
\cline { 2 - 3 } & High & Low & \\
\hline Yes & 42 & 14 & 0.01 \\
\hline No & 18 & 10 & \\
\hline
\end{tabular}

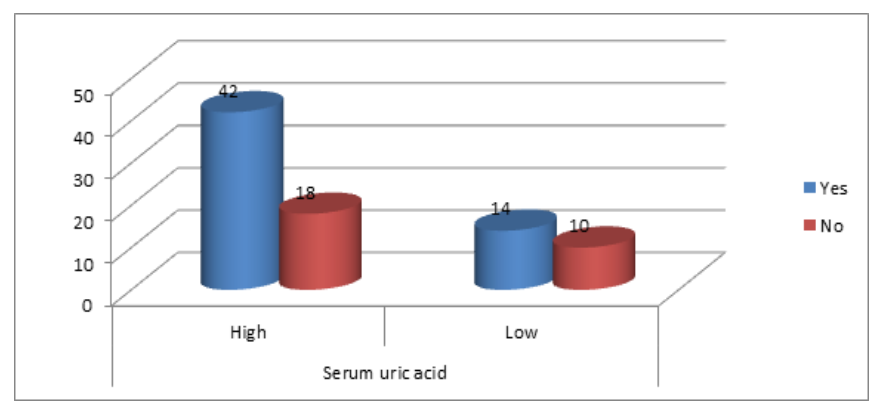

Figure 3: Association between Hypertension and Serum Uric Acid Levels
[Table 3] shows that out of 56 patients with hypertension, 42 had high and 14 had low serum uric acid level. Out of 28 patients who had not hypertension, 18 had high serum uric acid and 10 had low. The difference was significant $(\mathrm{P}<$ $0.05)$.

Table 4: Association between the Serum Uric Acid and Cerebrovascular Accident

\begin{tabular}{|l|l|l|l|}
\hline \multirow{2}{*}{ Stroke } & Serum uric acid & \multirow{2}{*}{ P value } \\
\cline { 2 - 3 } & High & Low & \\
\hline Yes & 28 & 20 & 0.01 \\
\hline No & 20 & 16 & \\
\hline
\end{tabular}

[Table 4] shows that among 48 patients who had stroke, 28 had high serum uric acid and 20 had low uric acid. The difference was significant $(\mathrm{P}<0.05)$.

Table 5: Association between the Serum Uric Acid and Urine Micro Albumin

\begin{tabular}{|l|l|l|l|}
\hline $\begin{array}{l}\text { Duration of } \\
\text { diabetes }\end{array}$ & Number & $\begin{array}{l}\text { Urine Micro } \\
\text { Albumin in Diabetes } \\
\text { Patients }\end{array}$ & $\begin{array}{l}\text { Urine Micro } \\
\text { Albumin }\end{array}$ \\
\hline $0-3$ & 52 & 5.12 & 38.6 \\
\hline $4-6$ & 46 & 6.34 & 46.5 \\
\hline $7-10$ & 24 & 7.16 & 53.2 \\
\hline$>10$ & 12 & 7.13 & 54.3 \\
\hline
\end{tabular}

[Table 5] shows that serum uric acid and urine micro albumin level was elevated with duration of diabetes mellitus.

\section{Discussion}

Recent studies reveal that high serum uric acid (SUA) could also be a risk factor for DN. Studies disagree on whether uric acid has oxidant or antioxidant properties. In vitro studies show that uric acid may have antioxidant properties. SUA works as a scavenger of free radicals, reacting with a series of oxidants, especially peroxynitrite. ${ }^{[5]}$ Other studies, both in vitro and in vivo, suggest that high levels of SUA may promote endothelial dysfunction, hypertension, and metabolic syndrome by inducing oxidative stress. In fact, there is evidence that the use of drugs that lower serum uric acid can revert these conditions. ${ }^{[6]}$ The present study was conducted to evaluate serum uric acid as a risk factor for micro- vascular complications of diabetes mellitus.

In present study, age group 40-60 years had 46, 60-80 years had 25 and $>80$ years had 13 patients. Hyperuricemia was positive in 56 and negative in 28 . Kodama et al, ${ }^{[7]}$ found that a total of 120 cases of type 2 Diabetes mellitus, out of which there were 69 males $(57.5 \%)$ and 51 females $(42.5 \%)$, with a mean age of $59.04 \pm 13.47$ years. Mean FBS was 186.10 $\pm 77.53 \mathrm{mg} / \mathrm{dl}$ with majority of the subjects having elevated FBS. Mean PPBS of $274.94 \pm 108.66 \mathrm{mg} / \mathrm{dl}$ and of HbA1c $8.15 \pm 1.7$ was observed. The uric acid of majority number of our study participant males $(65.22 \%)$ had level of $\geq 7.4$, with a mean of $9.53 \pm 4.38$. Mean blood urea and serum creatinine levels were $46.91 \pm 15.13$ and $1.44 \pm 0.29$ respectively. There was significant association seen between uric acid levels and urine albumin, serum creatinine, twenty four hour urinary albumin, FBS and PPBS levels and HbA1c levels.

Hyperinsulinemia as a consequence of insulin resistance 
causes an increase in serum uric acid concentration by both reducing renal uric acid secretion and accumulating substrates for uric acid production. The mean serum uric acid levels were elevated statistically highly significant in type 2 diabetic. ${ }^{[8]}$ Hyperuricemia is caused by muscle wasting and weight loss in diabetes mellitus15Chronic high glucose concentration causes tissue injury, in turn leads to increasing non-protein nitrogen substances. This phenomenon accounts for increased uric acid levels. Diabetic patients have a high risk of kidney disease due to hyperglycaemia, Hyperuricemia etc. Increased glycaemic index related with Hyperuricemia lead to changes in glomerular permeability. The highly significant values seen were due to dysfunction of the renninangiotensin system in long term diabetes. Type 2 diabetic patients have a long asymptomatic period of hyperglycaemia and many other conditions causing micro albuminuria but hypertension and long term diabetes are main risk factors. ${ }^{[9]}$

We found that out of 56 patients with hypertension, 42 had high and 14 had low serum uric acid level. Out of 28 patients who had not hypertension, 18 had high serum uric acid and 10 had low.

Among 48 patients who had stroke, 28 had high serum uric acid and 20 had low uric acid. Serum uric acid and urine micro albumin level was elevated with duration of diabetes mellitus. Many studies saw association with poor glycemic control and creatinine like study by El-Wakf et al. ${ }^{[10]}$ Uric acid levels also serve as an indicator of cardiac risk, which when raised in the cases of type $2 \mathrm{DM}$, further adds the cardiac risk which is already there due to diabetes.

\section{Conclusion}

Authors found that elevated serum uric acid levels in type 2 diabetes mellitus cause more micro vascular and macro vascular complications.

\section{References}

1. Heinig M, Johnson RJ. Role of uric acid in hypertension, renal disease and metabolic syndrome. Cleve Clin J Med 2006;73(12):1059-1064.

2. American Diabetes Association. Diagnosis and classification of diabetes mellitus. Diabetes Care 2014;37: 81-90.

3. Gagliardi AC, Miname MH, Santos RD. Uric acid: A marker of increased cardiovascular risk. Atherosclerosis 2009; 202(1):11-17.

4. Cook DG, Shaper AG, Thelle DS, et al. Serum uric acid, serum glucose and diabetes: relationships in a population Study. Postgrad Med J 1986;62(733):1001-1006.

5. Bonakdaran S, Hami M, Shakeri MT. Hyperuricemia and albuminuria in patients with type 2 diabetes mellitus. Iran J Kidney Dis 2011;5(1):2124.

6. Bandaru P, Shankar A. Association between serum uric acid levels and diabetes mellitus International Journal of Endocrinology 2011;2011:1-6.

7. Kodama S, Sugawara A, Saito K, et al. Association between serum uric acid and development of type 2 diabetes. Diabetes Care 2009;32(9):1737-1742.

8. Cirillo P, Sato W, Reungjui S, et al. Uric acid the metabolic syndrome and renal disease. J Am SocNephrol 2006;17(12 Suppl 3): 165-168.

9. Zoppini G, Targher G, Chonchol M, et al. Serum uric acid levels and incident chronic kidney disease in patients with type 2 diabetes and preserved kidney function. Diabetes Care 2012;35(1):99-104.

10. El-WakfAM, Abbas TM, El-Baz RA, et al. Role of hypertension and metabolic abnormalities in the development of diabetic nephropathy among Egyptian patients with type 2 diabetes. Nature and Science, 2011; 9(7):220-226

Copyright: () the author(s), 2019. It is an open-access article distributed under the terms of the Creative Commons Attribution License (CC BY 4.0), which permits authors to retain ownership of the copyright for their content, and allow anyone to download, reuse, reprint, modify, distribute and/or copy the content as long as the original authors and source are cited.

How to cite this article: Chauhan NS. To Evaluate Serum Uric Acid as a Risk Factor For Micro- Vascular Complications of Diabetes Mellitus. Acad. JMed.2019; 2(1):12-14.

DOI: dx.doi.org/10.21276/ajm.2019.2.1.4

Source of Support: Nil, Conflict of Interest: None declared. 